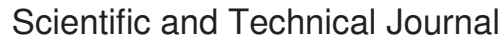 \\ Safety \& Defense 5(2) (2019) 47-53
}

\section{Methodological Basis of Logistic Support of the Air Force of the Armed Forces of Ukraine}

\author{
Volodymyr MIRNENKO \\ National Defense University of Ukraine named after Ivan Chernyakhovsky, Kiev, Ukraine; \\ email: MirnenkoVI@gmail.com, ORCID: 0000-0002-7484-1035 \\ Pavlo OPENKO \\ National Defense University of Ukraine named after Ivan Chernyakhovsky, Kiev, Ukraine; \\ email: pavel.openko@ukr.net,.ORCID:0000-0001-7777-5101 \\ Vitalii TIURIN \\ National Defense University of Ukraine named after Ivan Chernyakhovsky, Kiev, Ukraine; \\ email: tyurin_vitaly@ukr.net, ORCID:0000-0003-0476-7471 \\ Oleksii MARTYNIUK \\ National Defense University of Ukraine named after Ivan Chernyakhovsky, Kiev, Ukraine; \\ email: o.r.martyniuk@gmail.com, ORCID:0000-0003-2578-0018
}

\begin{abstract}
This article proposes a unified theory of logistics for the Air Forces of the Armed Forces of Ukraine based on the existing theories of armament and the logistics of the Armed Forces, and on the general laws and established consistent patterns, trends, principles, forms and methods of the use of the logistics of the Air Forces of the Armed Forces of Ukraine. The objective function of the logistics system of the Air Forces of the Armed Forces of Ukraine is formulated to achieve compliance of the capabilities of this system with the predicted volume of logistics tasks. In order to implement this compliance, it is necessary to ensure the convergence of requirements and capabilities at all levels of logistics management. The assessment of the functioning of the Air Forces logistics system of the Armed Forces of Ukraine is proposed on the basis of the stated views on the logistics theory of the Air Forces of the Armed Forces of Ukraine by assessing the set of real capabilities of each subsystem that is a part of its structure and system as a whole. At the same time, the assessment of the quality of the logistic support of the military units (formations) of the Air Forces of the Armed Forces of Ukraine should be related to the level of implementation of the potential capabilities of the logistics system when solving problems of each subsystem at the various stages of combat training, unblocking and operational deployment, the preparation and conduct of operations (combat actions), restoration of combat capability of troops (forces).
\end{abstract}

Keywords: logistics of the Air Forces of the Armed Forces of Ukraine, logistic system of the Air Forces of the Armed Forces of Ukraine, logistics. 


\section{Introduction}

The organizational structure of the logistics management bodies, the list of necessary assets of logistics, their functional duties and tasks were basically determined in accordance with the measures of the State Program for the Development of the Armed Forces of Ukraine up to 2020 (approved by the Decree of the President of Ukraine - Supreme Commander-in-Chief of the Armed Forces of Ukraine dated March 22, 2017 , No. 73/2017) concerning the creation of a unified logistics system of the Armed Forces of Ukraine as a result of the joint work of the General Staff of the Armed Forces of Ukraine and the interested military authorities.

The perspective logistics system of the Armed Forces of Ukraine (UAF) provides for a vertical division: planning (determination and planning of meeting troops' requirements) and executive (maintenance of necessary material resources and provision of troops with material resources and services). Therefore, a set of measures are planned to be taken in the Air Forces (AF) of the UAF in order to improve the logistic system by creating a planning and executive authority for managing logistics, providing air commanders with satisfying functions for providing logistical facilities, forming airbases for the provision of aviation brigades, and the transfer of certain military units of logistics to the air commands.

The current integrated logistic system of the AF of the UAF is a set of combined logistic command units of the command of the AF of the UAF, departments of logistics of air commands, services and units of the logistics and combat service support of military units (subdivisions) with subordinated assets of logistics, the number of which is determined by the combat composition, structure, tasks of the military units (subunits) of the AF of Ukraine and intended for solving the tasks of planning and the logistical support of the forces (forces), as well as the implementation of logistics measures of the military units (divisions) of the AF of Ukraine in their daily activities, during combat training, mobilization, operational deployment and combat readiness, preparation and conduct of hostilities, restoration of combat capability of military units (subunits) [1].

The logistic system of the AF of the UAF is designed to fulfill the tasks of logistics of military units (subunits) in the conduct of operations (combat actions) under any conditions of the situation. Its main tasks are: the definition of the requirements of the AF of the UAF as for the armament and military equipment (weapons and military equipment) and other material means (MM); planning the supply of weapons and other military equipment to military units (subunits); the organization of military transportation; the creation of immovable stocks; accumulation, storage and accounting of weapons and military equipment and other MMs;

the provision and organization of the transportation of weapons and military equipment; the organization of the operation of the weapons and military equipment of the nomenclature of logistics; the organization of the restoration of the weapons and military equipment of the nomenclature of logistics; logistics assets control; organization of airfield engineering support of aviation basing; control over the organization of airfield maintenance of flights in military units of the AF; and the organization of vital functions of military units (subunits).

The objective function of the logistic system of the AF of the UAF is formulated as the achievement of the compliance of the capabilities of this system with the predicted volume of tasks of logistics. In order to implement this condition, it is necessary to ensure that the requirements and capabilities are consistent across all levels of logistic management. Deviations from these conditions must be compensated within the set limits by the reserve of opportunities at each level of the hierarchy. In order to achieve this goal, the logistic system of the higher level, which is the logistics of the command of the AF of the UAF, must have a reserve of abilities to influence the lower level in case of critical situations appear. In this case, the scope and timing of the measures in the interests of air commands and units (subunits) of the UAF are determined.

\section{Analysis of recent research and publications}

An analysis of the logistic support systems of the leading countries of the world, NATO-member states (partner countries) [2-5] was carried out to determine the main views on the logistics theory of the AF of the UAF. In addition, an analysis of the logistic systems of the UAF [6] has been carried out and all elements of this system which participate in the combat service support of operations (combat actions) of military units (subunits) were examined. The approach of the decomposition of the logistic system of the AF of the UAF allowed for revealing the influence of each element on the implementation of its logistics functions.

When speaking about the logistic support system at the current stage, it should be noted that the AF is the only one service of the UAF in which logistics has been operating since 2004, when there was an attempt to approximate NATO standards concerning logistic support in the military sphere. It enables dealing with technical and logistics issues effectively, using an integrated approach to planning and organizing the implementation of security tasks. At the same time, combining the technical system and the logistic support system into a unified logistics system, as is currently the case in the AF, contributes to the guaranteed implementation of the tasks of support of subordinated troops, thus the unity of command determines the interconnection between the subsystems of technical support and logistic support.

The optimal composition and logistics structure of the AF of the UAF, improvement of forms and methods of logistic support, the development of logistics principles, management and elaboration of interaction methods contributed to the successful solution of tasks.

At the same time, the subsystem of the technical support for the AF of the UAF (under the nomenclature of logistics) requires improvement, as at present stage, separate technical support tasks are organized within different chains of command (there is no single authority who organizes the implementation of all kinds of logistics technical support). 
The development of the theoretical elaboration of the issues of logistic support for conducting operations (combat actions) is based on solving the logistic problems of the UAF, namely the search for ways to resolve the discrepancy between the desirable and the actual state of logistics, which is considered in the publications of Romanchenko I.S. [7, 10], Khazanovich O.I. [7], Tarasenko A.V. [8], Shuenkin V.O. [9, 10], Rolin I.F. [11], Servatyuk V.M. [12] and Krizhny A.V. [13].

In today's conditions of conducting operations (combat actions) the theory of armament and the theory of the rear services of the AF that exist separately, as components of military science, lose their functional purpose as partial theories.

Taking into consideration the modern forms and methods of conducting operations (combat actions), as well as requirements for forming a unified logistics system for the UAF and logistics, created management bodies, forces and means of logistic support of military units (subunits) of the UAF, the purpose of the article is to define the main provisions of the new the unified logistic theory of the AF of the UAF. In this context, the basis of the unified theory of logistics is the following methodologies:

- the methodology of system logistic analysis - a set of methods and techniques for the development, adoption and substantiation of solutions while examining, creating and managing of logistics systems;

- the methodology of the cybernetic approach to the management of logistics systems - the research of the logistics system based on the principles of cybernetics in particular through identification of direct and feedback links, the study of the set of processes of exchange, processing and transformation of information;

- the methodology of operations research - research of logistics system with the use of mathematical quantitative methods for substantiation of tasks of logistic support;

- forecasting methodology - a set of methods and techniques for forecasting the development of both the logistics system and its subsystems in dynamics.

\section{Presentation of the main research material.}

On the basis of the analysis of the logistic support of the AF of the leading countries of the world and NATO member-states (partner countries) [2-5], certain types of activities, requirements and tasks of logistic support [1], created logistic structures of military units (subunits) of the UAF, scientific methods of research of logistics, a unified theory of logistics for the AF of the UAF is proposed, which includes the following main components:

- the conceptual apparatus and the empirical basis of logistics of the AF of the UAF, which are based on the forms of scientific knowledge and contain scientific positions and results, as well as the mechanism of their implementation;

- initial conceptual provisions according to the types of logistics activities of the UAF, which consider and provide the development of the necessary methods for calculating the needs of forces and assets of logistics of the AF of the UAF;
- the main provisions for the preparation of the logistics infrastructure for the accumulation, $n$, separation and conservation of material resources, the use and replenishment of stocks, the operation of weapons and military equipment;

- increase of efficiency of logistics by activities;

- rules of logical conclusions which are based on the generalization of experience of creation and functioning of the logistics management bodies of the Armed Forces of the leading countries of the world and NATO member-states (partner countries), determine the direction of the longterm development of logistic support of military units (subunits) of the UAF providing the ability to integrate logistics systems while performing compliant operations.

That is, as for its structure, the theory of logistics of the AF of the UAF is an internally differentiated integral system of knowledge about material, transport, evacuation, information and financial flow processes according to types of activity, which characterizes the logical dependence on some elements from others, the derivation of the content of the theory of logistics from a certain set of statements and concepts according to the defined logical and methodological principles and rules, the basic components of which are: principles, axioms, postulates, laws, judgement, concept, categories and facts.

The analysis of the logistic support of military units (subunits) of the UAF indicates the availability of approaches as for the use of the proposed logistics theory. The main approaches the following:

- solving tasks according to the types of activity of logistics of the AF during the conduct of operations (combat actions) in the established scope of tasks and in interaction with the logistics systems of the Land Forces of the UAF, the Naval Forces of the UAF, other military formations and law-enforcement agencies of special assignment, defense industry, and other branches of the national economy of Ukraine;

- logistical maintenance of high autonomy of conducting operations (combat actions) of military units (subunits) of the UAF;

- maintenance of high maneuverability and mobility of military units (subunits) of the UAF in the conduct of operations (combat operations), which is provided by resettlement, transfer and promotion of military units (subdivisions) of the Airborne, development of the aerodrome network;

- creation and improvement of the logistic system of the AF of the UAF on the basis of a functional integrated system of logistics of the UAF;

- the capacity of the logistic system of the AF of the UAF to conduct operations in the operational groups of the Army (forces) of the UAF;

- achievement of high efficiency and functionality of logistic processes and their compatibility with the NATO logistics system by applying the relevant NATO standards in the activities of the AF of the UAF [14].

The basis of these approaches is the modular and territorial principles of logistics constructing the infrastructure for 
the provision of military units (subunits) of the UAF. In this case, the territorial system of logistics of the AF is represented by a multilevel hierarchical structure, the basis of which is logistics bodies. Organizationally, it includes the logistic bodies of the Command of the UAF, air commands, and military units of the AF. The logistic structure of the AF of the UAF will be brought in line with the typical structure of the logistics management bodies in all services of the UAF and the logistic units of the strategic level.

Methodologically, the central role of the formation of the proposed logistics theory of the AF of the UAF is to determine the patterns, trends, principles, forms and methods of logistic for conducting operations (combat actions) of military units (subunits) of the AF of the UAF, which are formed within the framework of the theory of logistics and relate to logistic support.

Analysis of the development of logistic support of the AF of the UAF enables the identification of patterns that reflect the stable links of the logistics system of the AF of the UAF, with the development of the branches of the national economy of Ukraine, the infrastructure of logistics and the transport system of the country. That is, for the logistic system of the AF of the UAF the dependence of the quality of the preparation, conduct and outcome of the operation (combat actions) on the state and capabilities of the logistic support system is inherent.

The complexity and interconnection of logistic support measures, namely, a clear and transparent logistic support management system (material, transport, evacuation, information and financial flows management) in the logistic system of the AF of the UAF give rise to the second regularity of its construction and functioning. This is expressed in a unity of infrastructure support of logistics of the AF of the UAF, which is an integral part of the engineering and infrastructure support of the UAF, both stationary and mobile, for the purpose of measuring of their vitality. The creation of a single logistic space of the UAF logistics system of the UAF within the framework will allow for fulfilling the requirements of logistics of the AF of the UAF in accordance with the modular and territorial principle of construction of the logistics infrastructure.

The next regularity of logistic support is the centralization of management and the decentralization of the implementation of the tasks of using the logistic system of the AF of the UAF provided that the assets of logistic support for conducting operations (combat actions) are sufficient.

Knowledge of the law allows us to understand the operation and properties of the logistics system and to form a more adequate decision-making model. In the future, the patterns are manifested in the form of trends that determine the existence and improvement of the logistics system of the AF of the UAF through the interaction of this system with the infrastructure of logistics, transport system and branches of the national economy of Ukraine.

On the basis of an analysis of the organization of the operation and development of logistics systems of NATO member-states (partner countries), in particular by examining the logistical support of the troops, it is possible to identify a number of stable tendencies that are related by the limitation of most resources, the high destructive ability of enemy weapons, and the speed of conducting operations (combat actions). The tendencies, which belong to the logistics of the AF of the UAF, are the following:

- centralization of planning and organization of logistics at the level of logistics Command of the UAF;

- the dependence of the organization and management of logistic support on the structure of the AF of the UAF, the material base and conditions for the implementation of logistic support;

- implementation of the territorial system of providing military units (subunits) regardless of their belonging to one or another service of the UAF;

- maintaining the proportionality and optimum correlation in the organization of logistic support of the AF of the UAF in the general system of logistics of the UAF;

- the unity of organizational and methodological foundations (organizational and information support, analysis, planning, control) of the logistic system of the AF of the UAF at all levels of logistic support;

- compatibility of logistic assets of interacting military units (subunits);

- reduction of intermediate levels of provision, concentration of major efforts in the air command and military units (subunits), where the expenditures of logistics are incurred;

- optimization of processes of making logistic decisions based on efficiency indicators used in the logistics of the AF of the UAF [15];

- automation of the processes of material, transport, evacuation, information and financial flows management [16];

- the dependence of the efficiency of the solution of the increasing scope of tasks of logistics of the AF of the UAF on the amount of information used.

Therefore, in order to solve the problem of processes optimization for making logistic decisions based on efficiency indicators used in the logistics of the AF of the UAF, the indices and criteria for evaluation of the effectiveness of the functioning of the prospective logistics system of the AF of the UAF have been developed.

The methodology includes [17]:

- assessment of the performance indicators of the logistics system of the UAF;

- analysis and generalization of performance evaluation indicators for various studied variants of logistics system contention and their verification with the use of relevant criteria;

- proposal development for the choice of rational structure of the management elements of the forces and means of logistic support of the UAF on the basis of the values of indicators and verification of criteria for various studied variants of logistics system construction.

Indicators and criteria for the effectiveness of logistics system are divided into groups (directions), which are used for:

- assessment of temporary indicators of the accomplishment of tasks by the logistic support by the group of troops; evaluating the required resource; 
- evaluating the quantitative and qualitative involvement of personnel, weapons and equipment of the logistics divisions of the group of forces;

- evaluating accounting, organizing the supply of weapons and other materiel, repair and restoration of weapons and equipment;

- military evaluation of the organizational structure.

Trends in practice are realized through the principles of logistic support, which are consistent with legislative acts on national security and defense of Ukraine, NATO logistics standards, and determine the specifics of the functioning of military units (subunits) of the UAF in the course of the preparation and conduct of operations (combat actions).

In essence, the principles of logistic support represent a provision according to which the necessary properties of the logistic system of the AF of the UAF are formed. At the same time, the principles of logistic support provide the basis for the construction and operation of the logistics system of the AF of the UAF.

When using these principles in practice, it is possible to justify the recommendations for carrying out a complex of measures to determine the tasks of logistics, the order of management of the logistic system, the volume of weapons and military equipment, logistics and the order of their transportation and supply, the sequence, timing, methods of action, interaction, the necessary composition of the group of forces and logistics, the development of appropriate planning documents on troop-contributing tasks in peace and war time.

The basis for systems of intellectual support of life cycle of the knowledge-intensive products are databases about products where statistical data, arrived from military units with armament and military equipment (AME), is saved. Results of processing this statistical data and developments of recommendations of further operation of AME sample and other data arrays about a product [18] are kept in these databases.

In work the structure of technical support system of AME of the AF of UAF is offered. The structure provides control of operation, technical state and recovery of military products in a common information space.

Basis of information support system is the AME database of Ukraine which is created at a development stage and scientific and technical maintenance of the corresponding AME sample. The database is stored and refined during production, operation, combat use, write-off, utilization. It comprises all technical information about a military product and its components, with obligatory use of the database of the Logistic of the UAF concerning existence and the movement of stores.

The Control Center of operation, technical state and recovery of military products (analog of the center of logistic support of life cycle of complex technical products) is created in the Logistic of the AF Command.

The main tasks of the Control Center are [20]:

- collecting and the analysis of technical data on a state, service conditions and resource expenses of AME samples, types and causes of failures, level of readiness of attending personnel;
- elaboration of the nomenclature of military and technical facilities and the set of spare parts, tools and accessories which is contained in storehouses of military units of AF;

- determination of work amounts, use of repair bodies and use of military and technical facilities during intermediate and capital repairs of AME samples (as necessary), big interval maintenance of AME samples, maintenance (scheduled works / preventive maintenance) of them, monitor and recovery works on AME samples which are subject of transfer to maintenance on technical condition, control of a limit condition of AME samples which are operated on technical condition;

- providing applications for repair (replacement) of knots, blocks, subblocks, units with the plant facilities, repair bodies, providing centers of the Logistic of Ukraine, storehouses, bases and arsenals of UAF.

Devices for monitor and diagnostic of technical state of a military product are one of basic elements of perspective technical support system of AME of the UAF. Elements of these means as a part of the automated test system have to be constantly in AME samples and provide timely receiving, processing and transfer of data about the product technical state for formation of control decisions. The formation of control decisions with use of the AME databases of UAF is provided by support system of decision-making (SSDM) of the person which makes the decision based on data about the product technical state [20]. At the present time, an example to solve a problem of optimization of processes of making logistic decisions used in the logistics of the AF of the UAF during operation of compound technical objects (CTO) (AME of the UAF) two strategies of maintenance and repair are used: regulated strategy of maintenance and repair and strategy of maintenance and repair according to state [21].

The method of planning to move complex technical objects to repair during the operation according to the state it is in divides the same type of complex technical objects into two groups. CTO from the first group will not need repair during the next year. CTO from the second group needs repair during the next year. In addition, for CTO from the second group, the order of repair is defined according to the minimum time of achievement of no-failure operation index limit value.

Practical use of this method of planning of moving CTO into repair during operation according to its state requires the execution of following actions [21]:

- complex technical objects operation according to its state with the accumulation of data about CTO failures;

- quarterly estimation of mean-time-to-failure of each compound technical object;

- execution of the limit state check of compound technical objects;

- verification of limit state achievement of the compound technical object;

- $\quad$ prediction of the mean-time-to-failure for the next year;

- verification of mean-time-to-failure achievement of limit value;

- determination of quarter when the mean-time-to-failure achieves to the limit value; 
- planning of moving CTO into repair for the next year in the quarter which is previous to the quarter when the meantime-to-failure achieves to the limit value;

- execution of repair of a complex technical object according to its state.

The results of limiting state checks of complex technical objects and the results of their operation between these checks are the initial data for the application of the method of planning of moving CTO into repair during operation according to its state. If, during the limit state check, the limit state of a complex technical object is fixed, the object will need immediate repair according to its state. For other CTO, according to the result of the operation, the quarterly estimation of mean-time-to-failure is made.

Thus, in accordance with the General Provisions of the Logistic Doctrine of the UAF [1], the principles of logistic support are the following:

Priority - is the determination of the directions of concentration of the main assets of logistics in order to fulfill of the priority and most important tasks of the troops (forces);

Sufficiency - timely provision of necessary weapons and military equipment and logistic support in accordance with determined requirements;

Efficiency - use of assets of logistic support with the achievement of the maximum possible result;

Flexibility - a proactive approach with the ability to adapt and respond quickly to changing circumstances;

Transparency - the exchange of reliable information as for the requirements and availability of weapons and military equipment, and logistic support at services at all levels, taking into account the degree of access to it (ensuring the protection of confidential information);

Coordination - is the interaction of all components of the logistic system of the AF of the UAF to provide an effective functioning of the system in general, as well as with the logistics system of the UAF, the bodies of foreign states, international organizations and armed forces of other states on the basis of the concluded international treaties of Ukraine, NATO -members states;

Responsibility - the logistics departments of all levels in their activities must strictly adhere to the powers granted and be responsible for the timely execution of specified tasks;

Cooperation - cooperation between the AF of the UAF and other components of the defense forces, central and local executive authorities, local government authorities, state enterprises of the military industrial complex, other enterprises of the national economy of Ukraine, as well as with the authorities of foreign states, international organizations and armed forces of others states on the basis of concluded international treaties of Ukraine as for logistic support. Cooperation should be directed towards meeting the requirements of the UAF in an effective and timely manner;

Interoperability - the logistics of the UAF aims to achieve full interoperability with NATO logistics, which will enable the integration of systems in the course of joint operations, as well as the possibility of using individual weapons and military equipment samples and logistics nomenclature of NATO member-states (partner countries) for meeting the requirements of the UAF;

Stability - the organization of logistic support should include measures aimed at minimizing losses of allocated resources from the influence of certain factors (external and internal, positive and negative), and in the course of operations (combat actions) from the influence of the enemy.

Together with the established laws, tendencies and principles of logistic support, the AF of the UAF require the concept of forms and methods to be defined. In essence, forms of logistic support represent the actions of the logistics management authorities regarding the use of logistic assets. In the meantime, the forms of logistic support are directly related to the forms of action of the military units (subunits) of the UAF and are important in the operation of the logistic system of the UAF. Therefore, the main forms of logistic support of military units (subunits) of the UAF are:

- Logistic support for combat training and combat duty;

- Logistic support for everyday activities;

- Logistical support for mobilization, operational deployment and bringing into combat readiness;

- Logistic support for operational and tactical regrouping;

- Logistic support for the preparation and conducting of operations (combat actions);

- Logistic support for the restoration of combat capability of military units (subunits).

In turn, as part of the logistical support for the preparation and conduct of operations (combat actions) it is expedient to identify:

- Logistic support for military units (subunits) of the UAF in defense operations;

- Logistic support for the preparation of military units (subunits) of the UAF for a counter-offensive (offensive) operation during a defensive operation;

- Logistic support for military units (subunits) of the UAF in the counter-offensive (offensive) operation;

- Logistic support for military units (subunits) of the UAF in the air operations of the UAF;

- Logistic support of aircraft maneuvers of the AF of the UAF of Ukraine;

- Logistic support for the regrouping of military units (subunits) of the UAF.

The implementation of these forms is carried out by means of logistic support. On the basis of the analysis of logistics systems in the leading countries of the world and NATO member-states, it is possible to define the content the "methods of logistic support" concept. This concept implies the complex of questions of theory and practice that characterize the order and methods of using assets of logistic support for the tasks of preparation and conduct of operations (combat actions). In this case, the logistics support methods will depend on:

- the nature and methods of conducting operations (combat actions) of military units (subunits) of the UAF;

- directions of concentration of the main efforts of logistics;

- the available assets of logistic support and the sequence of their application; 
- the degree of centralization of the management of the logistics system and decentralization of the tasks of logistic support;

- physical and geographical conditions of the area of operation and the nature of the deployment of assets of logistic support on the ground;

- the nature of the maneuver and the regrouping of forces and means of logistic support.

Combinations of these factors determine a number of specific methods of logistic support that characterize the proposed forms of logistic support for military units (subunits) of the UAF in the course of the conduct of operations (combat actions). The choice of specific methods of logistic support for the AF of the UAF will be determined by the Deputy Chief of the logistics unit - Chief of the logistics of the AF in the process of making a decision on the organization of logistic support in the preparation and conduct of operation (combat actions). Changes in conditions during the conduct of operations (combat actions) will change the combination of factors, as well as the change in the methods of logistics in general. In the subsystems of logistic support of the AF of the UAF, at operational and tactical levels, each form of logistic support will correspond only to the inherent methods of these forms.

\section{Conclusions and perspectives of further research.}

In conclusion, while taking into consideration the stated views on the logistics theory of the AF of the UAF, the functioning of the logistics system of the AF of the UAF should be assessed on the basis of the requirements for logistic support by assessing the totality of real capabilities of each subsystem that is part of it and the system as a whole. In this case, the assessment of the quality of logistic support for military units (subunits) of the UAF can be related to the degree of implementation of the potential capabilities of the logistic system in solving the tasks of each subsystem during the stages of combat training, mobilization and operational deployment, the preparation and conduct of operations (combat actions), and the restoration of combat capability of troops (forces).

\section{References:}

[1] Order of the Ministry of Defence of Ukraine of October 11, 2016, No. 522 "Basic Provisions of the Logistic Support of the Armed Forces of Ukraine" [in Ukrainian].

[2] Sumets A.M. Logistics in the Armed Forces of NATO and the Bundeswehr [Electronic resource] / A.M. Sumets Logistic Time. - Access mode: http://logisticstime.com/news/logistika-v-vooruzhennyx-silaxnato-i-bundesvera [in Ukrainian].

[3] NATO 2020: Assured security; Dynamic engagement - analysis and recommendations of the group of experts on a new strategic concept for NATO [Electronic resource]. - Access mode: http://www.nato.int/ strategicconcept/expertsreport.pdf.

[4] Combat Service Support (FM 4-0) [Electronic resource]. - Access mode: http://tsg3.us/tnsg_lib/unit_dig_lib/fm4_0.pdf.

[5] David Beaumont. Logistics in the war [Electronic resource]. - Access mode: http://www.sgs-mil.org/logistika/412-logistika-v-voine-hast-1.html\#sel=6:3,64.

[6] Kotov, O.B., Gurin, O.M., Novichonok, S.M. (2012). Views on the improvement of the logistics of the Air Forces of the Armed Forces of Ukraine. Collection of scientific works of Kharkiv University of Air Forces, 1 (30), 39-42 [in Ukrainian].

[7] Romanchenko, I.S., Khazanovich, O.I, Trehubenko, S.S. (2015). Logistics systems Modeling: Monograph. Lviv: Hetman Petro Sahaidachnyi National Army Academy [in Ukrainian].

[8] Tarasenko, A.V. (2013). Scientific approaches to the definition of "logistics of security and defence sector entities". European perspectives, 7, 54-59 [in Ukrainian].

[9] Shuenkin, V.O. (2007). Logistics - what is it? Science and defence, 1, 66-68 [in Ukrainian].

[10] Romanchenko, I.S., Shuenkin, V.O. (2007). Views on the development of the logistics system of the Armed Forces of Ukraine. Science and defence, 4, 22 - 27 [in Ukrainian].

[11] Rolin, I.F., Morozov, I.E., Minko, O.V. (2017). Contents of the main terms in the field of logistic support for military formations. Armament systems and military equipment, 1 (49), 61 - 64 [in Ukrainian].

[12] Servatyuk, V.M., Ugrynovych, O.I. (2013). Perspective directions of reformation of the logistics system of the Armed Forces of Ukraine. Science and Technology of the Air Forces of the Armed Forces of Ukraine, 2 (11). 14-18 [in Ukrainian].

[13] Krizhny, A.V., Openko, P.V., Drannik, P. A. (2015). Prospects for the development of the technical support system for anti-aircraft missile troops. Problems of creation, testing, application and operation of complex information systems, 10, 148-157 [in Ukrainian].

[14] Order of the Ministry of Defense of Ukraine dated August 22, 2017, No. 450 "On ensuring the functioning of the military standardization system" [in Ukrainian].

[15] P.V. Open'ko, P.A. Drannyk, V.V. Kobzev, M.B. Brovko, G.S. Zalevsky (2017). Substantiation of reliability requirements for mobility means of surface-to-air missile systems. Advances in Military Technology vol. 12, 1, pp. 91-99.

[16] Zaklad, M.A., Biletov, V.I., Leoncheva, K.O. (2013). Automation of the rear. Defensive Herald of the Center for Military and Security Policy, 4, 26-29 [in Ukrainian].

[17] Zalevskyi, H.S., Lekakh, A.A., Hurin, O.M., Startsev, V.V. and Kalachova, V.V. (2019). Indicators and criterias of general points of the methodology of estimative efficiency of the implementation of logistic support of the military units of the Air Force of the Armed Forces of Ukraine in the armed warfare, Scientific Works of Kharkiv National Air Force University, Vol. 3(61), 45-52. https://doi.org/10.30748/ zhups.2019.61.07 [in Ukrainian].

[18] V.V. Voinov, G.M. Zubritsky, M.B. Brovko, D.M. Zapara (2013). Improvement of the Ukrainian Air Force technical support with the help of new information technologies introduction, Science and Technology of the Air Force of Ukraine, Vol. 3(12), pp. 27-31 [in Ukrainian].

[19] V.O. Tarasov, B.M. Gerasimov, I.O. Levin, V.O. Kornijchuk (2007). Intellectual System of Decision Making: Theory, Synthesis, Efficiency [In Russian]. Kyiv: MAKHC, $336 \mathrm{p}$.

[20] V. Tyurin, O. Barabash, P. Openko, I. Sachuk, A. Dudush (2017). Informational Support System for Technical State Control of Military Equipment. IEEE 4th International Conference "Actual Problems of Unmanned Aerial Vehicles Developments (APUAVD)", October 2017, Kyiv: National Aviation University, pp. $242-244$.

[21] I. Sachuk, S. Bortnovskyi, A. Artemenko, A. Kalyta, P. Openko, V. Tyurin (2018). Recommendations for Practical Use of the Planning Method of Compound Technical Objects Exit into Repair During Operation According to State. IEEE First International Conf. "System Analysis \& Intelligent Computing (SAIC)", October 2018, Kyiv: Igor Sikorsky Kyiv Polytechnic Institute, pp. 121-124. 